JEL: C13, C22, G10, G15

DOI: 10.5937/industrija43-8036

UDC: $330.138: 519.8$

005.521:005.334

Original Scientific Paper

\title{
A Conditional Extreme Value Theory Approach in Value-at-Risk Forecasting: Evidence from Southeastern Europe and USA market
}

Article history:

Received: 5 April 2015

Sent for revision: 11 June 2015

Received in revised form: 16 September 2015

Accepted: 17 September 2015

Available online: 30 December 2015

\begin{abstract}
As a consequence of the recent financial crisis, the adequacy of different Value-at-Risk (VaR) methodologies was heavily questioned. Current practice in VaR assessment relies on modeling the whole distribution of returns. As an alternative, in this paper we model tail behavior of returns, and thus VaR, using conditional Extreme Value Theory (EVT), which combines EVT and GARCH methodology. Moreover, we examine the performance of conditional EVT with the daily returns of seven stock market indices, of which six are from Southeastern Europe (BelexLine, BET, BUX, CROBEX, SBITOP, SOFIX) from the period of September 2004 - April 2013, and one from USA market (Standard\&Poors 500 Index) from the period January 1998 - April 2013. Backtesting of historical daily returns proves that conditional EVT model gives good predictions for all indices and for all confidence levels.
\end{abstract}

Keywords: Value-at-Risk, Extreme Value Theory, volatility, fat-tails, heteroscedasticity

\section{Uslovni pristup teorije ekstremnih vrednosti u proceni Vrednosti-pod-Rizikom: dokazi sa tržišta jugoistočne Evrope i SAD}

Apstrakt: Kao posledica skorašnje finansijske krize, adekvatnost različitih metodologija za procenu vrednosti-pod-rizikom (VaR) se često dovodi u

\footnotetext{
${ }^{1}$ Faculty of Organizational Sciences, University of Belgrade, selena@fon.rs
} 
Totić S.: A Conditional Extreme Value Theory Approach in Value-at-Risk Forecasting...

pitanje. Ustaljena praksa u proceni VaR-a se oslanja na modelovanje cele distribucije prinosa. Kao alternativa takvom pristupu, u ovom radu se modeluju repovi distribucije prinosa, a samim tim i VaR, primenom uslovnog pristupa teorije ekstremnih vrednosti (EVT) koji kombinuje EVT i GARCH metodologiju. Rad ispituje performanse uslovnog pristupa teorije ekstremnih vrednosti, primenjenog na dnevne prinose sedam indeksa od kojih su šest indeksi tržišta u razvoju jugoistočne Evrope (BelexLine, BET, BUX, CROBEX, SBITOP, SOFIX) za period September 2004 - April 2013, a jedan je indeks tržišta SAD (Standard\&Poors 500 indeks) za period Januar 1998 - April 2013. Rezultati back testiranja su pokazali da uslovni pristup teorije ekstremnih vrednosti daje dobre rezultate za sve indekse i za sve nivoe poverenja.

Ključne reči: vrednost-pod-rizikom, teorija ekstremnih vrednosti, volatilnost, debeli repovi, heteroskedastičnost

\section{Introduction}

The last two decades proved to be very turbulent for financial markets worldwide - the Asian financial crisis in 1997-1998, followed by the dot-com bubble in 1997-2000 and the recent credit crisis starting in 2007. As a consequence, the problem of quantifying and managing market risk has become one of the major concerns of market regulators and financial institutions worldwide. Mostly due to its conceptual simplicity among different risk measures, Value-at-Risk (VaR) grew to be an industry standard. In 1994, J.P. Morgan introduced VaR to the general public in a RiskMetrics technical document. Moreover, at the Bank for International Settlements in 1996, the Basel Committee on Banking Supervision published a document "Amendment to the capital accord to incorporate market risks" promoting the use of VaR for capital requirements assessment in financial institutions. The foundations of VaR methodology were proposed in more detail by Jorion (1997), and Duffie and Pan (1997), which defined it as the maximum potential loss in value of a portfolio of financial instruments with a given probability over a certain horizon.

Two most common ways of VaR estimation are: analytical approach and historical simulation. Analytical approach assumes that returns follow a known distribution, such as normal. Since returns commonly exhibit significant autocorrelation and heteroscedasticity, conditional distribution of returns is typically modeled. By employing ARCH/GARCH volatility modeling techniques, the heteroscedasticity can be eliminated or reduced. However, the main weakness of these approaches is that the assumption of conditional normality does not seem to hold for real data. In their paper, Jondeau and Rockinger (2003) used a database consisting of daily stock-market returns for 
Totić S.: A Conditional Extreme Value Theory Approach in Value-at-Risk Forecasting...

20 countries to test for similarities between the left and right tails of returns. Their results confirmed that none of these returns proved to be normally distributed. Da Silva and Mendes (2003) obtained similar results while studying ten Asian stock markets. Another problem is the stylized fact that financial returns show significant leptokurtosis or "fat-tails" (Mandelbrot, 1963), which parametric models, assuming normal distribution, fail to capture. An alternative to the normal distribution may be to consider a Student-t distribution which has heavier tails than the normal one. However, this distribution maintains the hypothesis of symmetry that is not often present in financial returns.

On the other hand, historical simulation estimates return distribution of a portfolio with the empirical distribution of past returns, thus avoiding distributional assumptions. This method practically lets the past data speak for itself, while assuming that the past will be a good proxy of the future. However, this model has some serious drawbacks, such as choice of window size and dependence on a particular data set. From the point of view of robustness it is desirable to use very long historic data periods, but this implies that observations from the distant past will have the same impact on VaR estimation as the recent observations. Additional problem is that historical simulation VaR cannot assess the events that did not happened in a particular historical sample period, but may happen in the future.

The fact that VaR deals with the extreme quantiles of the returns' distribution, whereas previously mentioned models deal with the whole distribution, gives more intuition for modeling tail behavior. This is the exact focus of Extreme Value Theory (EVT), which is the probability theory that studies the distribution of extreme realizations under certain assumptions. The most valuable feature of this theory is that it concentrates on modeling tail behavior with some asymptotic distribution, thus omitting pitfalls of previously mentioned parametric approaches. This is of crucial importance for risk management which aims to prevent huge unexpected losses.

In this paper predictive performance of conditional EVT model proposed by McNeil and Frey (2000) is studied. For testing the performance of this VaR model we use a dataset which consists of seven indices - S\&P500 as a representative of USA market and six indices from Southeastern European emerging markets: Bulgarian (SOFIX), Croatian (CROBEX), Hungarian (BUX), Romanian (BET), Slovenian (SBITOP) and Serbian (BELEXline). The S\&P500 index is chosen as a representative of the most developed financial market. The objective was to study the behavior of financial returns on two types of different markets - one developed and six markets which belong to the same emerging market of Southeastern Europe, since we presume that these markets have different characteristics, especially in terms of volatility. On the other hand, countries of Southeastern Europe have gone through 
Totić S.: A Conditional Extreme Value Theory Approach in Value-at-Risk Forecasting...

some major changes, such as liberalization of national markets, transition and EU integration. However, financial markets of these countries were developing in a rather slow pace, remaining small in terms of trading volume and rather shallow in terms of liquidity. The period chosen for S\&P500 is last 15 years, since it covers some major financial downturns, whereas for indices of Southeastern Europe countries it is 9 years, since "the youngest" index BELEXLine was established in 2004. Given that at different confidence levels VaR models tend to perform differently, in this paper we use three confidence levels $-0.95,0.99$ and 0.995 . In order to assess risk of both long and short position investors, both tails of return distribution were estimated. Finally, the performance of the model was tested with the conditional coverage test.

\section{Literature review}

The foundations of the EVT were set by Fisher and Tippett (1928) and Gnedenko (1943), who proved that the distribution of the extreme values of an independent and identically distributed (iid) sample from a distribution function $F$, when adequately rescaled, can converge to one of the following distributions: Gumbel, Weibull, and Fréchet distribution. However, among the first authors who applied EVT in risk management practice were McNeil $(1997,1998)$, and Danielsson and de Vries (1997). In one of their first papers, McNeil (1998) used block maxima techniques of EVT methodology for VaR estimation, whereas Danielsson and de Vries (1997) used semi-parametric approach based on the Hill-estimator. Moreover, given that aforementioned iid assumption of EVT is often violated with financial returns, McNeil and Frey (2000) proposed a conditional EVT framework. This framework is a two-step procedure that models firstly the correlation structure of the observations by fitting, e.g., a GARCH model to the data, and afterwards performs the estimation of parameters of the GPD distribution of obtained GARCH residuals (since they are considered as iid). On the other hand, Nystrom and Skoglund (2002) proved that maximum likelihood estimators, being compared to Hill estimators, give better estimates of parameters of Generalized Pareto distributions for all quantiles above 95\%. Moreover, they proved that maximum likelihood estimator is almost invariant to the choice of threshold.

More recent studies were mainly focused on relative performance of VaR models. Kuester et al. (2006) analyzed more than fifteen VaR models on 30 years of NASDAQ data and proved that EVT VaR combined with GARCH gives the best estimations. Similarly, Chan and Grey (2006), Marinelli et al. (2007) and Totic et. al. (2011) showed that EVT models had better predictive performance than conventional models for VaR assessment. 
Totić S.: A Conditional Extreme Value Theory Approach in Value-at-Risk Forecasting...

Further research was done in the field of application of EVT models for risk estimation in emerging markets. Jondeau and Rockinger (2003) used GEV distribution to analyze tail behavior of indices from Asian, Eastern European and Latin American markets. Gancay and Selcuk (2004) examined nine emerging markets and proved that EVT based VaR models outperformed all others. Assaf (2009) analyzed tail behavior of market indices of four MENA countries and showed that returns distributions are fat-tailed and adequately modeled with EVT. Uppal (2013) examined conditional EVT estimates for five emerging markets (Brazil, China, India, Mexico, South Africa) in the period prior to global financial crisis and in the crisis period. Results proved that conditional EVT model fits well indices behavior in both periods. Djakovic et al. (2011) investigated the performance of GPD application to raw returns of major indices of Serbian, Croatian, Slovenian and Hungarian markets for the period 2006-2009. In this paper, we extend these samples and enrich it with two more indices for Romanian and Bulgarian market, while applying GPD to $\mathrm{GARCH}$ residuals in order to account for heteroscedasticity.

\section{Methodology}

\subsection{Value-at-Risk}

VaR is an attempt to produce a single number that summarizes the downside risk of the trading portfolio. It is defined as the potential loss (with specified probability) from adverse market movements over a fixed time horizon, assuming that the portfolio is not managed during that period (Alexander, 2001).

If we denote the price of an asset at time $t$ as $P_{t}$, then the return of an asset at time $t r_{t}$ can be calculated as $r_{t}=\ln \left(\frac{P_{t}}{P_{t-1}}\right)$. Given that $\mathrm{VaR}$ is maximum potential loss over one day horizon, with the confidence level $\alpha \epsilon(0,1)$, daily VaR for period $t+1$ can be expressed as following:

$$
P\left(r_{t+1} \leq \operatorname{VaR}_{t, \alpha}\right)=\alpha
$$

Being an industry standard for calculating capital requirements for risk purposes, it is of great importance to adequately model behavior of financial returns. In order to capture the main features of financial returns as fat-tails and volatility clustering we will use peaks over threshold (POT) method of EVT and GARCH model. 
Totić S.: A Conditional Extreme Value Theory Approach in Value-at-Risk Forecasting...

\subsection{Extreme Value Theory - Peaks over Threshold model}

From the previous section, we have seen that VaR represents the quantile of the distribution of returns, and therefore it is related to the tails of the distribution of the underlying data. To model the distribution of tails we argue to use an extreme value theory method called peak over threshold (POT) method. This method is based on extracting the extremes from a sample of observations, which are defined as the exceedances over a predetermined, high threshold $u$ and modeling the distribution of exceedances over this threshold.

Let $\mathrm{X}_{1}, \mathrm{X}_{2}, \ldots, \mathrm{X}_{\mathrm{n}}$ be a sequence of independent and identically distributed random variables with the distribution function $F$. An exceedance over predefined threshold $u$ is defined by $Y_{i}=X_{i}-u$ and occurs each time when $X_{t}>u$ for any $t=1, \ldots, n$. The behavior of exceedances over threshold $Y_{i}$ is modeled with the conditional probability function $F_{u}$ which is of the following form:

$$
\begin{gathered}
F_{u}(y)=P(X-u<y / X>u)=\frac{P(X<y+u, X>y)}{P(x>y)}, \quad 0 \leq y<x-u \\
<=>F_{u}(y)=\frac{F(y+u)-F(u)}{1-F(u)}
\end{gathered}
$$

Since $\mathrm{x}=\mathrm{y}+\mathrm{u}$ for $\mathrm{X}>u$, we have the following representation for distribution function $F$ :

$$
F(x)=F_{u}(y)(1-F(u))+F(u)
$$

Due to scarcity of the data above threshold, the estimation of the conditional distribution $F(u)$ is a complex task. At this point EVT gives a useful solution for conditional excess distribution function which is stated in the following theorem.

Theorem 1. (Pickands,1974, Balkema \& de Haan, 1975) Let $\left(X_{n}\right)$ be a set of $n$ independent and identically distributed random variables with common distribution function $F$. Let $X_{F}$ the end of the upper tail of $F$, possibly a positive infinity. If $F$ is such that the limit given by Theorem 1 exists, there are constants $\xi, \beta>0$ such that $F_{u}(y)$ for large threshold is well approximated by:

$$
\lim _{u \rightarrow x_{F}} \sup _{0<y<x_{F}-u}\left|F_{u}(y)-G_{\xi, \beta}(y)\right|=0
$$

where

$$
G_{\xi, \beta}(y)=\left\{\begin{array}{r}
1-\left(1+\frac{\xi y}{\beta}\right)^{-\frac{1}{\xi}}, \xi \neq 0 \\
1-e^{-\frac{y}{\beta}}, \xi=0
\end{array}\right.
$$


Totić S.: A Conditional Extreme Value Theory Approach in Value-at-Risk Forecasting...

$G_{\xi, \beta}$ is the so called generalized Pareto distribution (GPD).

The parameter $\beta>0$ is a scale parameter, whereas $\xi$ is the shape parameter, or tail index. The value of parameter $\xi$ indicates heaviness of the tail: the greater the $\xi$, the heavier the tail. Additionally, the tail index $\xi$ determines the type of three extreme value distributions. If $\xi=0$, the distribution is Gumbel with infinite left and right tails; characteristic for thin-tailed distributions of returns. If $\xi<0$, the distribution is Weibull and has an upper bound. Finally, if $\xi>0$, the distribution is Fréchet and has a lower bound, characteristic for fattailed distributions of returns. The previous theorem states that for a large $u$, the excess distribution above this threshold may be taken to be exactly GPD for some $\xi$ and $\beta$.

The GPD estimation involves two steps: the choice of threshold and the parameter estimation. The choice of threshold is basically a compromise between choosing a lower threshold that gives enough observations for parameter estimation (some observations may come from the center of the distribution), leading to less volatile and more biased estimators, and choosing a higher threshold so Theorem 1 holds, but generating few excesses and thus making the estimators more volatile and less biased. $\xi$. We will use results of McNeil and Frey (2000) who suggested using the largest $10 \%$ of the realized losses for a threshold. Moreover, for parameter estimation we will use maximum likelihood estimators.

After the parameters of GP distribution are obtained, the next step is the application of GP distribution to quantile estimation of high out of sample quantiles. The crucial question is how to make use of Generalized Pareto distributions in an estimate of the unknown distribution $F$ of random variables $X_{i}$. Since $F_{u}(y)$ belongs to Generalized Pareto family of distributions, we are left with the estimation of $F(u)$. According to historical simulation method $F(u)$ can be estimated as $\left(n-N_{u}\right) / n$, where $N_{u}$ is the number of exceedances over a given threshold $u$ and $n$ is the total number of observations. By putting the HS estimate of $F(u)$ in equation (4) and employing GPD parameters, we get the tail estimator:

$$
\hat{F}(x)=1-\frac{N_{u}}{n}\left(1+\hat{\xi} \frac{x-u}{\widehat{\beta}}\right)^{-\frac{1}{\xi}}
$$

which is only valid for $\mathrm{x}>u$. Alternatively, we can set $F(u)$ at some predefined level (for example 0.95), and then from the sample size (for example 1000) determine corresponding $N_{u}$ (in this example it would be 50). Furthermore, threshold can be found as the $\left(n-N_{u}\right)$ observation $X_{\left(n-N_{u}\right)}$, if all observations are ordered from the lowest to highest. 
Totić S.: A Conditional Extreme Value Theory Approach in Value-at-Risk Forecasting...

Inverting the previous equation for a given probability $q>F(u), \mathrm{VaR}$ is obtained:

$$
\widehat{\operatorname{VaR}}_{q}=u+\frac{\widehat{\beta}}{\widehat{\xi}}\left(\frac{n}{N_{u}}(1-q)^{-\widehat{\xi}}-1\right)
$$

\subsection{Conditional Extreme Value Theory}

As already mentioned, financial returns often exhibit autocorrelation and volatility clustering effect, which are both violating iid assumption of EVT. Therefore, in order to manage dependence in the time series of financial returns we will use conditional extreme value theory model proposed by McNeil and Frey (2000). This model suggests application of peaks over threshold method for modeling tail behavior of residuals obtained with GARCH model. In this case we used GARCH $(1,1)$ model with constant mean equation:

$$
\begin{aligned}
& r_{t}=\mu+a_{t} a_{t}=\sigma_{t} \varepsilon_{t} \text { and } \varepsilon_{t} \sim N(0,1)=>a_{t} \sim N\left(0, \sigma_{t}^{2}\right) \\
& \sigma_{t}^{2}=\alpha_{0}+\alpha_{1} a_{t-1}^{2}+\beta_{1} \sigma_{t-1}^{2}
\end{aligned}
$$

where $\alpha_{0}>0, \alpha_{1}>0, \beta_{1}>0$ and $\alpha_{1}+\beta_{1}<1$. From the GARCH model we obtain one period ahead variance forecast and standardized residuals $\varepsilon_{i}$. We assume that excess residuals over predefined threshold $u=\varepsilon_{N_{u}+1}\left(\mathrm{~N}_{\mathrm{u}}\right.$ is the number of data in tail which is fixed) follow Generalized Pareto distribution. The tail estimator is then:

$$
\hat{F}(x)=1-\frac{N_{u}}{n}\left(1+\hat{\xi} \frac{\varepsilon-u}{\widehat{\beta}}\right)^{-\frac{1}{\xi}}
$$

For $q>1-\frac{N_{u}}{n}$, inverting the previous formula gives:

$$
\widehat{\operatorname{VaR}}(\varepsilon)_{q}=\varepsilon_{N_{u}+1}+\frac{\widehat{\beta}}{\widehat{\xi}}\left(\left(\frac{n}{N_{u}}(1-q)\right)^{-\widehat{\xi}}-1\right)
$$

which is the $q$-th quantile of residuals. Using the conditional variance forecast for one period ahead and $q$-th quantile of residuals we obtain one day VaR at 1-q confidence level:

$$
\operatorname{VaR}_{q}=\sigma_{t+1} \operatorname{VaR}(\varepsilon)_{q}
$$

\subsection{Conditional Coverage Test (Cristoffersen test)}

VaR models assume that exceptions should be independently distributed over time. If the exceptions exhibited some type of "clustering", then the VaR 
Totić S.: A Conditional Extreme Value Theory Approach in Value-at-Risk Forecasting...

model may fail to capture returns variability under certain conditions, which could represent a potential problem. If the VaR measure accurately reflects the underlying portfolio risk then the chance of violating today's VaR should be independent of whether or not yesterday's VaR was violated.

Christoffersen test is based on breaking up the null hypothesis into two subhypotheses: the sub-hypothesis that the model generates the correct frequency of tail losses, and the sub-hypothesis that tail losses are independent. These two sub-hypothesis are practically summed into one which says that the hit series $I_{t}(\alpha)^{2}$ is independent and identically distributed and has Bernoulli distribution. To test this hypothesis, a likelihood ratio test of conditional coverage is used:

$L R_{c c}=2\left(\mathrm{n}_{00} \ln \left(\frac{1-\widehat{\pi}_{01}}{1-\alpha}\right)+\mathrm{n}_{01} \ln \left(\frac{\widehat{\pi}_{01}}{\alpha}\right)+\mathrm{n}_{10} \ln \left(\frac{1-\widehat{\pi}_{11}}{1-\alpha}\right)+\mathrm{n}_{11} \ln \left(\frac{1-\widehat{\pi}_{11}}{1-\alpha}\right)\right.$

where $n_{i j}$ denotes the number of observations of the hit sequence with a $j$ following an $i$. Moreover $\widehat{\pi}_{01}$ and $\widehat{\pi}_{11}$ are obtained as maximum likelihood estimates of $\pi_{i j}=P\left(I_{t}=j / I_{t-1}=i\right)$ :

$$
\begin{aligned}
& \hat{\pi}_{01}=\frac{n_{01}}{n_{00}+n_{01}} \\
& \hat{\pi}_{11}=\frac{n_{11}}{n_{10}+n_{11}}
\end{aligned}
$$

This test is asymptotically distributed as $x^{2}$ with two degrees of freedom. The acceptance region for the null hypothesis is between zero and critical value of $\mathrm{X}^{2}$ with two degrees of freedom. Therefore, if the value of $L R_{c c}$ is in this region we may claim that the VaR model generates the correct frequency of tail losses, and that the tail losses are independent.

\section{Empirical Results}

In this study we examined the predictive performance of conditional EVT in VaR estimation on S\&P500 index for the period January 1998 - April 2013 and six indices from Southeastern Europe for the period of September 2004 April 2013. We estimated one day VaR for both tails of returns' distributions and examined model consistency at confidence levels of 0.95, 0.99 and 0.995. We used "rolling-window" concept with window size of 1000

${ }^{2} \mathrm{Hit}$ function is defined in the following manner: $I_{t}(\alpha)= \begin{cases}1 & \text { if } \quad x_{t} \leq-V a R_{t-1, \alpha} \\ 0 & \text { if } \quad x_{t} \geq-V a R_{t-1, \alpha}\end{cases}$ 
Totić S.: A Conditional Extreme Value Theory Approach in Value-at-Risk Forecasting...

observations. According to this concept, the one period ahead return forecast is calculated using the data from the previous 1000 observations. For S\&P500 index we used 2853 "rolling-windows" for each tail and confidence level, whereas for BELEXline we used 1158, for BET we used 1132, for BUX we used 1149, for CROBEX we used 1098, for SBITOP we used 1130 and for SOFIX we used 1107. Different number of "rolling windows" is a consequence of different number of working days of stock exchanges in countries across Southeastern Europe. All the calculations were performed in MATLAB software version R2009a.

\subsection{Data Analysis}

Before VaR assessment and backtesting preliminary data analysis was conducted. The results are given in the following table.

Table 1. Descriptive Statistics

\begin{tabular}{lccccccc}
\hline & S\&P500 & $\begin{array}{c}\text { BELEX } \\
\text { line }\end{array}$ & BET & BUX & CROBEX & SBITOP & SOFIX \\
\hline Mean & 0.0001 & 0.0000 & 0.0001 & 0.0001 & 0.0001 & -0.0001 & -0.0001 \\
\hline Median & 0.0006 & 0.0000 & 0.0002 & 0.0002 & 0.0002 & 0.0000 & 0.0001 \\
Maximum & 0.1100 & 0.0990 & 0.0459 & 0.0572 & 0.0642 & 0.0363 & 0.0317 \\
\hline Minimum & -0.0950 & -0.0700 & -0.057 & -0.054 & -0.0467 & -0.0366 & -0.0493 \\
$\begin{array}{l}\text { Standard } \\
\text { deviation }\end{array}$ & 0.0130 & 0.0100 & 0.0082 & 0.0077 & 0.0061 & 0.0052 & 0.0060 \\
\hline $\begin{array}{l}\text { Skewness } \\
\text { Kurtosis }\end{array}$ & -0.186 & 0.260 & -0.494 & -0.085 & 0.051 & -0.457 & -0.894 \\
$\begin{array}{l}\text { Jarque- } \\
\text { Berra }\end{array}$ & 10.063 & 14.671 & 6.617 & 6.013 & 13.342 & 7.564 & 8.577 \\
$\begin{array}{l}\text { statistic } \\
\text { Hi square } \\
\text { with 2 d.o.f. }\end{array}$ & 5.991 & 5.991 & 5.991 & 5.991 & 5.991 & 5.991 & 5.991 \\
$\begin{array}{l}\text { Number of } \\
\text { observations }\end{array}$ & 3853 & 2158 & 2132 & 2149 & 2098 & 2130 & 2107 \\
$\begin{array}{l}\text { Ljung Box Q } \\
\text { Ljum }\end{array}$ & 4995.3 & 737.4 & 1019.7 & 2049.8 & 2126.8 & 1833.6 & 2358.5 \\
\hline
\end{tabular}

Source: Author

For all indices mean proved to be zero, which is also often cited stylized fact of daily financial returns. Standard deviation for S\&P500 is slightly higher, which is contrary to the intuition that emerging markets should be more volatile. However, this may be due to relatively low liquidity of emerging markets when compared to USA market. Among emerging markets the most volatile is Serbian market, which can be associated with the highest country risk and overall stability. Skewness is negative for majority of the indices, meaning that the tail on the left side is longer or fatter, than the right side, 
Totić S.: A Conditional Extreme Value Theory Approach in Value-at-Risk Forecasting..

whereas for BELEXline and CROBEX is positive. Kurtosis for all indexes is high, especially for BELEXline and CROBEX giving indication of strong presence of fat-tails. Moreover, high values of Jarque-Berra test statistics prove that returns for all indexes strongly deviate from normality. This deviation from normality and fat-tails of returns of S\&P500 and BELEXline indices can be seen even better from the following $Q Q$ plot graphs (these indices were chosen since they have the highest value of Jarque-Berra statistic).

Graph 1. QQ Plots of BELEXline

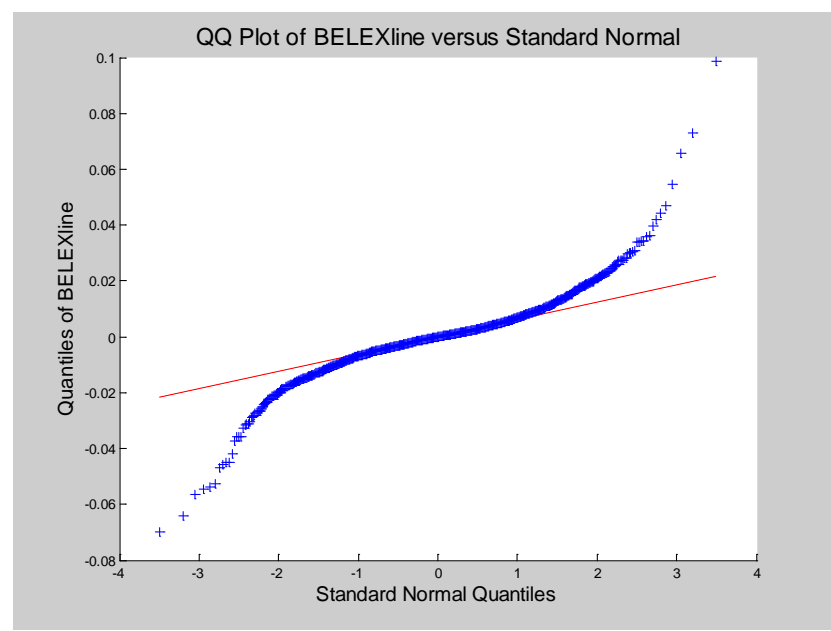

Graph 2. QQ Plots of S\&P500

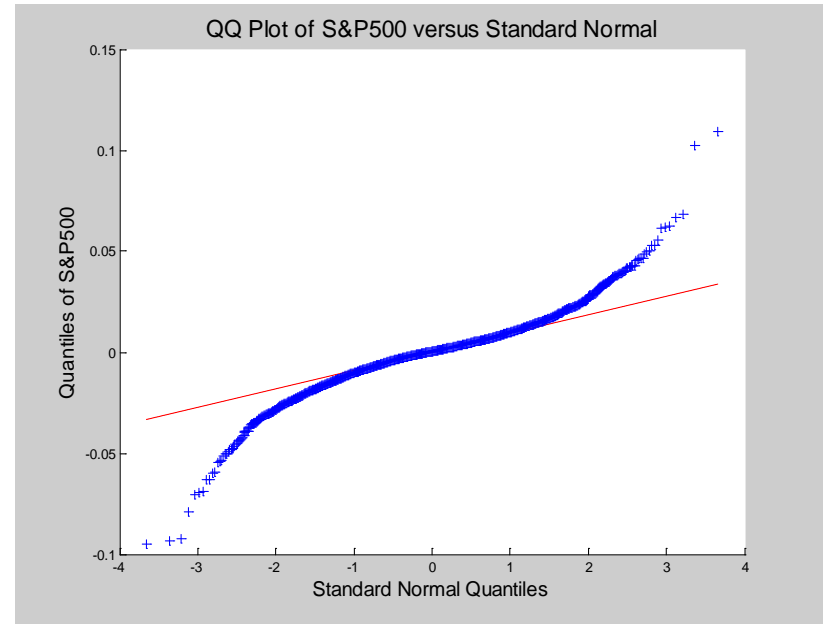


Totić S.: A Conditional Extreme Value Theory Approach in Value-at-Risk Forecasting...

Finally to test the presence of volatility clustering we tested the autocorrelation of squared residuals. The Ljung Box Q statistic for all indices is significantly above critical value of 31.404 , thus we can conclude that heteroscedasticity is strongly present in the data. The preliminary data analysis in both cases confirmed the stylized facts about financial returns such as fat-tails and volatility clustering, thus giving us incentive to use conditional EVT model for modeling VaR.

\subsection{Backtesting}

Testing precision and predictive performance of VaR model is a crucial step for validation of risk measurement system. Regarding this, backtesting gives a statistical framework for testing whether realized returns are in line with VaR prediction. In its simplest form backtesting compares the number of breaches of $\mathrm{VaR}$ (violations- when realized return was below $\mathrm{VaR}$ ) and compares it with confidence level used. For example, if we consider $99 \%$ VaR, violation should occur in $1 \%$ of the returns. With this simple technique, we obtain the following results for lower tail VaR (Table 2.) and for upper tail VaR (Table 3.)

Table 2. Number and percentage of VaR violations for lower tail

\begin{tabular}{lccc}
\hline & \multicolumn{2}{c}{ Number and percentage of VaR violations } \\
\hline Confidence level & 0.95 & 0.99 & 0.995 \\
\hline Predicted for S\&P500 & $143(5 \%)$ & $28(1 \%)$ & $14(0.5 \%)$ \\
\hline Realized for S\&P500 & $133(4.66 \%)$ & $26(0.91 \%)$ & $12(0.42 \%)$ \\
\hline $\begin{array}{l}\text { Predicted for } \\
\text { BELEXLine }\end{array}$ & $58(5 \%)$ & $12(1 \%)$ & $6(0.5 \%)$ \\
\hline $\begin{array}{l}\text { Realized for } \\
\text { BELEXLine }\end{array}$ & $54(4.66 \%)$ & $5(0.43 \%)$ & $5(0.43 \%)$ \\
\hline Predicted for BET & $57(5 \%)$ & $11(1 \%)$ & $6(0.5 \%)$ \\
\hline Realized for BET & $45(3.97 \%)$ & $13(1.15 \%)$ & $5(0.44 \%)$ \\
\hline Predicted for BUX & $57(5 \%)$ & $11(1 \%)$ & $6(0.5 \%)$ \\
\hline Realized for BUX & $51(4.44 \%)$ & $12(1.04 \%)$ & $7(0.61 \%)$ \\
\hline Predicted for CROBEX & $55(5 \%)$ & $11(1 \%)$ & $5(0.5 \%)$ \\
\hline Realized for CROBEX & $41(3.7 \%)$ & $8(0.73 \%)$ & $3(0.27 \%)$ \\
\hline Predicted for SBITOP & $57(5 \%)$ & $11(1 \%)$ & $6(0.5 \%)$ \\
\hline Realized for SBITOP & $57(5 \%)$ & $10(0.88 \%)$ & $4(0.35 \%)$ \\
\hline Predicted for SOFIX & $55(5 \%)$ & $11(1 \%)$ & $5(0.5 \%)$ \\
\hline Realized for SOFIX & $48(4.34 \%)$ & $6(0.54 \%)$ & $3(0.27 \%)$ \\
\hline
\end{tabular}

Source: Author 
Totić S.: A Conditional Extreme Value Theory Approach in Value-at-Risk Forecasting...

Table 3. Number of VaR violations for upper tail

\begin{tabular}{lccc}
\hline & \multicolumn{2}{c}{ Number and percentage of VaR violations } \\
\hline Confidence level & 0.95 & 0.99 & 0.995 \\
\hline Predicted for S\&P500 & $143(5 \%)$ & $28(1 \%)$ & $14(0.5 \%)$ \\
\hline Realized for S\&P500 & $143(5 \%)$ & $30(1.05 \%)$ & $18(0.63 \%)$ \\
\hline Predicted for BELEXLine & $58(5 \%)$ & $12(1 \%)$ & $6(0.5 \%)$ \\
\hline Realized for BELEXLine & $57(4.92 \%)$ & $6(0.51 \%)$ & $4(0.34 \%)$ \\
\hline Predicted for BET & $57(5 \%)$ & $11(1 \%)$ & $6(0.5 \%)$ \\
\hline Realized for BET & $50(4.42 \%)$ & $14(1.12 \%)$ & $11(0.97 \%)$ \\
\hline Predicted for BUX & $57(5 \%)$ & $11(1 \%)$ & $6(0.5 \%)$ \\
\hline Realized for BUX & $66(5.74 \%)$ & $10(0.87 \%)$ & $5(0.43 \%)$ \\
\hline Predicted for CROBEX & $55(5 \%)$ & $11(1 \%)$ & $5(0.5 \%)$ \\
\hline Realized for CROBEX & $50(4.55 \%)$ & $6(0.55 \%)$ & $2(0.18 \%)$ \\
\hline Predicted for SBITOP & $57(5 \%)$ & $11(1 \%)$ & $6(0.5 \%)$ \\
\hline Realized for SBITOP & $64(5.66 \%)$ & $14(1.24 \%)$ & $4(0.53 \%)$ \\
\hline Predicted for SOFIX & $55(5 \%)$ & $11(1 \%)$ & $5(0.5 \%)$ \\
\hline Realized for SOFIX & $48(4.34 \%)$ & $11(0.99 \%)$ & $7(0.63 \%)$ \\
\hline
\end{tabular}

Source: Author

Different number for predicted VaR violations across indices is for the reason that we have different number of observations for each index. From the backtesting prospective the closer the number of realized violations to the number of predicted violations, the better the model. In our case, we can see that for 95\% confidence level for lower and upper tail the model slightly overestimates VaR. For $99 \%$ and $99.5 \%$ confidence levels for both tails the number of $\mathrm{VaR}$ violations is in most cases almost exactly the same as predicted.

However, counting the number of violations and calculating its percentage is just the first step in backtesting process. In order to test the risk measurement model we need more powerful test that will include not only the frequency of violations but also dependence structure of violations. Therefore, we conducted Christoffersen Conditional coverage test. The results for both tails are given in the following two tables - Table 4 and Table 5. 
Totić S.: A Conditional Extreme Value Theory Approach in Value-at-Risk Forecasting...

Table 4. Conditional coverage test - lower tail

\begin{tabular}{|c|c|c|c|c|c|c|}
\hline \multirow{3}{*}{ DATA } & \multicolumn{6}{|c|}{ Confidence level } \\
\hline & \multicolumn{2}{|c|}{0.95} & \multicolumn{2}{|c|}{0.99} & \multicolumn{2}{|c|}{0.995} \\
\hline & $\begin{array}{l}\text { Likelihood } \\
\text { ratio }\end{array}$ & $p$ value & $\begin{array}{l}\text { Likelihood } \\
\text { ratio }\end{array}$ & $p$ value & $\begin{array}{l}\text { Likelihood } \\
\text { ratio }\end{array}$ & $p$ value \\
\hline Expected & 5.99 & 0.05 & 5.99 & 0.05 & 5.99 & 0.05 \\
\hline S\&P500 & 1.22 & 0.54 & 0.71 & 0.7 & 0.48 & 0.79 \\
\hline BELEXline & 2.68 & 0.26 & 4.83 & 0.09 & 0.92 & 0.15 \\
\hline BET & 12.67 & 0.00 & 2.46 & 0.29 & 0.12 & 0.94 \\
\hline BUX & 0.80 & 0.67 & 0.28 & 0.87 & 0.35 & 0.84 \\
\hline CROBEX & 4.27 & 0.12 & 1.02 & 0.60 & 1.38 & 0.50 \\
\hline SBITOP & 0.44 & 0.80 & 0.33 & 0.85 & 0.57 & 0.75 \\
\hline SOFIX & 1.45 & 0.48 & 2.87 & 0.24 & 1.41 & 0.49 \\
\hline
\end{tabular}

Source: Author

Table 5. Conditional coverage test - upper tail

\begin{tabular}{|l|c|c|c|c|c|c|}
\hline \multirow{2}{*}{ DATA } & \multicolumn{5}{|c|}{ Confidence level } \\
\cline { 2 - 7 } & \multicolumn{2}{|c|}{$\mathbf{0 . 9 5}$} & \multicolumn{2}{c|}{$\mathbf{0 . 9 9}$} & \multicolumn{2}{c|}{$\mathbf{0 . 9 9 5}$} \\
\cline { 2 - 7 } & $\begin{array}{c}\text { Likelihood } \\
\text { ratio }\end{array}$ & $p$ value & $\begin{array}{c}\text { Likelihood } \\
\text { ratio }\end{array}$ & $p$ value & $\begin{array}{c}\text { Likelihood } \\
\text { ratio }\end{array}$ & $p$ value \\
\hline \hline Expected & 5.99 & 0.05 & 5.99 & 0.05 & 5.99 & 0.05 \\
S\&P500 & 1.82 & 0.4 & 0.71 & 0.7 & 1.14 & 0.57 \\
BELEXline & 0.51 & 0.77 & 3.34 & 0.19 & 0.65 & 0.72 \\
BET & 1.11 & 0.57 & 0.95 & 0.62 & 4.19 & 0.12 \\
BUX & 1.32 & 0.52 & 0.38 & 0.83 & 0.14 & 0.93 \\
CROBEX & 1.61 & 0.45 & 2.80 & 0.25 & 2.96 & 0.23 \\
SBITOP & 2.51 & 0.29 & 0.96 & 0.62 & 0.09 & 0.96 \\
SOFIX & 4.37 & 0.11 & 2.80 & 0.25 & 0.45 & 0.80 \\
\hline
\end{tabular}

Source: Author

The first and the most important result from both tables is that Conditional EVT VaR model is correct for all indexes and for both tails at all confidence levels ( $p$ values are all above 5\%). The model is rejected only once for lower tail of BET index at $95 \%$, which is due to significantly lower number of VaR 
Totić S.: A Conditional Extreme Value Theory Approach in Value-at-Risk Forecasting...

violations than predicted, hence the model overestimated VaR. Moreover, $p$ values are in majority of the cases high, which confirms that Conditional EVT model strongly holds. This is vital, since we tested the model at seven very different markets - one very big and developed market and six markets which are rather small and shallow. In addition, we can clearly see that fat-tails are adequately modeled since at high confidence levels likelihood ratio statistics are very low, which is usually not the case with other parametric models. Also, asymmetry in returns is well captured since results for upper and lower tails are different. Finally, given that the data for all indices were chosen to cover stress periods, we can conclude that the model is robust.

\section{Conclusion}

In this paper we investigated predictive performance of conditional EVT VaR model of seven indexes - S\&P500, BELEXline, BET, BUX, CROBEX, SBITOP and SOFIX. Both tails of returns distributions were estimated serving as a proxy of investors' long and short positions. Preliminary data analysis proved that distributions of returns for all indices were not normally distributed. Moreover, results confirmed presence of fat-tails, meaning that probability of high impact losses/gains on these markets is significant. This is an important result, especially for the markets with negative skewness, for the reason that it indicates high risk of great losses. In addition, data analysis found that volatility clustering is strongly present on these markets. These facts present crucial challenges for risk managers while assessing risk and trying to capture specific risk behavior in these markets. With this in mind, we proposed and tested conditional EVT methodology on all markets of Southeastern Europe. Obtained results proved that for all confidence levels this methodology models adequately tail behavior of returns.

The main contribution of this study is that it produces quantitative and qualitative insight into tail risk of SE emerging markets and its modeling. So far, research and practice on these markets relies mostly on conventional models for $\mathrm{VaR}$ assessment, which adequately capture ether volatility clustering effect (EWMA, GACRH models) or fat-tails (historical simulation or pure EVT models). In this paper, the applied VaR methodology was tailored to fit specific characteristics of SE markets. Moreover, the robustness of methodology was tested through choice of time period, which included periods before, during and after global financial crisis. For Serbian market this is the first study in which conditional EVT approach is successfully applied and backtested.

For all of the above mentioned reasons, we find that results of this study are very useful for risk management and investment professionals in the process 
Totić S.: A Conditional Extreme Value Theory Approach in Value-at-Risk Forecasting...

of risk quantification and investment analysis. However, the scope for further research lies in expanding univariate conditional EVT analysis to multivariate cases which are applicable to real investment portfolio.

\section{References}

Alexander, C. (2001). Market Models. Chichester, England: John Wiley \& Sons Ltd..

Balkema, A.A., \& de Haan, L. (1974). Residual Life Time at Great Age. Annals of Probability, 2(5), 792-804. 2(5): 792-804. doi:10.1214/aop/1176996548

-Bank for International Settlement (BIS). (1996). Amendment to the capital accord to incorporate market risks. Basel, Switzerland: Basel Committee on Banking Supervision.

Christoffersen, P. (2004). Backtesting Value-at-Risk: A Duration-Based Approach. Journal of Financial Econometrics, 2(1), 84-108. 2(1): 84-108. doi:10.1093/jjfinec/nbh004

Danielsson, J., \& de Vries, C. (1997). Tail index and quantile estimation with very high frequency data. Journal of Empirical Finance, 4(2-3), 241-257. doi:10.1016/S0927-5398(97)00008-X

Da Silva, L.C.A., \& de de Melo Mendez, B.V. (2003). Value-at-Risk and extreme returns in Asian stock markets.International Journal of Business, 8(1), 17-40. Retrieved from Social Science Research Network. Retrieved from http://dx.doi.org/10.2139/ssrn.420266

Duffie, D., \& Pan, J. (1997). An overview of Value-at-Risk. Journal of Derivatives, 4(3), 7-49. doi:10.3905/jod.1997.407971

Fisher, R.A., \& Tippett, L.H.C. (1928). Limiting forms of the frequency distribution of the largest or smallest member of a sample. Mathematical Proceedings of the $\begin{array}{llll}\text { Cambridge } \quad \text { Philosophical } \quad \text { Society, 24(02), } & \text { 24(02): } 180 .\end{array}$ doi:10.1017/S0305004100015681

Gencay, R., \& Selcuk, F. (2004). Extreme value theory and Value-at-Risk: Relative performance in emerging markets.International Journal of Forecasting, 20, 287303. doi:10.1016/j.ijforecast.2003.09.005

Gnedenko, B. (1943). Sur La Distribution Limite Du Terme Maximum D'Une Serie Aleatoire. Annals of Mathematics, 44(3), 44(3): 423. doi:10.2307/1968974

Jondeau, E., \& Rockinger, M. (2003). Testing for differences in the tails of stockmarket return. Journal of Empirical Finance, 10(5), 559-581. doi:10.1016/S09275398(03)00005-7

Jorion, P. (1997). Value at Risk: The new benchmark for controlling market risk. Chicago, USA: McGraw-Hill..

Kuester, K., Mitnik, S., \& Paolella, M.S. (2006). Value-at-Risk prediction: A comparison of alternative strategies. Journal of Financial Econometrics, 4(1), 53-89. doi:10.1093/jifinec/nbj002

Mandelbrot, B. (1963). The Variation of Certain Speculative Prices. Journal of Business, 36(4), 36(4): 394. doi:10.1086/294632

Mcneil, A.J. (1997). Estimating the Tails of Loss Severity Distribution Using Extreme Value Theory. ASTIN Bulletin, 27(1), 1117-1137. doi:10.2143/AST.27.1.563210

Mcneil, A.J. (1998). Calculating quantile risk measures for financial return series using extreme value theory. Zurich, Switzerland: Department of Mathematics, Swiss 
Totić S.: A Conditional Extreme Value Theory Approach in Value-at-Risk Forecasting...

Federal Technical University. Retrieved from e-collection ETH Institutional Repository. Retrieved from http://dx.doi.org/10.3929/ethz-a-004320029

Mcneil, A.J., \& Frey, R. (2000). Estimation of tail related risk measure for heteroscedastic financial time series: An extreme value approach. Journal of Empirical Finance, 7(3), 271-300. doi:10.1016/S0927-5398(00)00012-8

Nyström, K., \& Skoglund, J. (2002). A framework for scenario-based risk management. Stockholm, Sweden: Working Paper, Swedbank, Retrieved from gloria-mundi. com.. Retrieved from http://gloria-mundi.com/UploadFile/2010-2/knjs.pdf

Pickands, J. (1975). Statistical Inference Using Extreme Order Statistics. Annals of Statistics, 3(1), 119-131. 3(1): 119-131. doi:10.1214/aos/1176343003 